\title{
O sonho dos mil gatos
}

Neste momento de transição em que assumo a tarefa de editor do JP, convido a nossa comunidade a refletir sobre o nosso jornal.

Os elementos básicos de uma revista científica são periodicidade e excelência científica; estes só podem ser obtidos caso uma comunidade científica forte o apóie. Não é de estranhar que o JP, em paralelo ao crescimento da SBPT, tenha obtido várias conquistas recentes. Nos últimos oito anos, quando o Dr. Carlos Alberto Pereira e a Dra. Thaís Queluz estiveram à frente do JP, caminhamos a passos largos. Na gestão do Dr. Pereira conquistamos periodicidade impecável. Na gestão da Dra. Thaís Queluz o JP foi indexado na base de dados da Bireme - Scientific Electronic Library On-line (SciELO) ${ }^{(1)}$. A base de dados SciELO indexou até o momento apenas 92 das cerca de 500 publicações brasileiras. Os títulos são selecionados depois de uma análise da periodicidade, corpo editorial, valor científico dos artigos, entre outros. O objetivo da SciElO é selecionar em torno de 100 revistas que representem algo entre $80 \%$ e $90 \%$ das citações de revistas nacionais ${ }^{(2)}$.

A produção científica brasileira é crescente. A nossa produção científica, aferida através de artigos publicados em periódicos científicos indexados na base de dados do Institute for Scientific Information (ISI), quadruplicou dos anos 80 até hoje. Se em 1981 a produção científica brasileira representava $0,44 \%$ da produção mundial, pulamos para $1,44 \%$ em 2001. Parece pouco, mas representamos mais de $42 \%$ da produção científica da América Latina $^{(2)}$. No caso da pneumologia, pude observar um salto enorme de nossa participação internacional com os meus próprios olhos. Em 1991, ao apresentar no congresso da American Thoracic Society (ATS) os dados de minha tese de doutorado, realizada no Laboratório de Poluição Atmosférica Experimental (que agora alberga o $\mathrm{JP})$, contávamos o número de brasileiros nos dedos das mãos. Atualmente, a SBPT organiza um já tradicional jantar durante a ATS que congrega aproximadamente 120 brasileiros. Nos congressos não somos apenas ouvintes. Nos congressos internacionais, um grande número de trabalhos científicos é apresentado por membros da SBPT. Nos últimos 10 anos a nossa massa crítica de pesquisa se multiplicou. Inúmeros brasileiros fizeram estágios de todos os tipos em importantes centros de todo o mundo. A distância entre os brasileiros e os "estrangeiros" está cada vez menor. O recente Congresso Brasileiro de Pneumologia, realizado em São Paulo, contou cerca de 2.500 inscritos. O nosso congresso não foi simplesmente um fórum de atualização, mas inúmeros trabalhos científicos de ótimo nível foram apresentados. O fato de uma delegação do American College of Chest Physicians ter vindo para o nosso congresso indica que o mundo de fato está mudando e as distâncias não são mais as mesmas.

No mundo da ciência as regras são claras. O sonho de todo pesquisador, inclusive dos brasileiros, é ter seus trabalhos publicados em revistas de alto impacto. O impacto científico de uma revista pode ser aferido através do número de vezes que os seus artigos são citados por outras publicações científicas ${ }^{(3)}$. Sabemos que as revistas científicas que realmente contam são poucas e estão concentradas nos países desenvolvidos, deixando as dos em desenvolvimento classificadas no final de longas listas ${ }^{(4)}$. Obviamente, os nossos melhores trabalhos são exportados. A imagem em espelho é de que damos pouco valor ao que é nosso, pois a visibilidade internacional de nossas revistas é baixa. A pergunta é: será que a tecnologia representada pela Internet poderia nos ajudar? Aparentemente, sim. Estudos recentes demonstram que o número de citações de uma revista aumenta quando os trabalhos são disponíveis gratuitamente na Internet ${ }^{(5)}$ e as revistas científicas podem aumentar o seu fator de impacto ao disponibilizar os seus artigos de forma eletrônica ${ }^{(6)}$. Portanto, a SciELO não representa somente um fim, mas, na realidade, um meio. Um pequeno estudo publicado em forma de carta na Nature, uma das mais prestigiosas revistas científicas do planeta, mostra que a SciELO pode ajudar, e muito. Nesse estudo, os autores selecionaram cinco revistas brasileiras indexadas no ISI e demonstraram que o fator de impacto das publicações pesquisadas mais do que duplicou após a sua indexação na SciELO(7).

Um dos grandes fossos que ainda nos separam da comunidade internacional é a língua inglesa, a língua oficial da ciência na atualidade. Nosso objetivo é o de traduzir e disponibilizar os artigos originais do JP em inglês na SciELO. Essa não é uma tarefa fácil ou barata e contamos mais uma vez com o apoio indispensável da SBPT. Se numa ponta precisamos aumentar o nosso rigor científico, $e$ isso pode representar, por exemplo, maior dificuldade para publicar no JP (atualmente, $30 \%$ dos artigos são rejeitados), pretendemos, também, aumentar a nossa proximidade com a nossa sociedade. Durante o recente Congresso Brasileiro de Pneumologia, 987 participantes deram a sua opinião sobre o que pensam do JP ao preencher um questionário. Essa adesão sem precedentes só foi possível graças ao estímulo de sorteio de livros doados por inúmeros autores. Por absoluta falta de espaço edito- 
rial, a opinião da sociedade sobre o $\mathrm{JP}$, bem como os ganhadores dos livros sorteados, estarão disponíveis na Internet, no site JP www.jornaldepneumologia.com.br. O nosso objetivo é ter uma avaliação não somente quantitativa, mas também qualitativa sobre o JP. Solicitamos três opiniões - quais os pontos positivos, negativos e quais as sugestões para o JP. Envie sua carta eletronicamente para o e-mail editorjp@terra.com.br. Esta sessão é aberta para todos os leitores do JP; precisamos mais uma vez de sua inestimável contribuição. As melhores cartas serão publicadas.

O JP está amadurecendo. Seguindo o modelo da SBPT, o próximo editor do JP, Prof. Dr. José Antonio Baddini Martinez, já está participando ativamente do Conselho Editorial do nosso jornal, não apenas como um revisor de artigos, mas como um verdadeiro editor associado. O JP está assumindo uma difícil e delicada tarefa de administrar propagandas que eram anteriormente terceirizadas. Teremos mais controle de nossas ações e isso demandará mais organização. Uma outra grande mudança estrutural é a passagem de nossa secretária de tempo parcial para tempo integral. A secretária do JP, Priscilla Bovolenta, que foi treinada para o cargo pela Dra. Thaís Queluz em Botucatu, aceitou o convite e o desafio de vir para São Paulo, garantindo um trabalho impecável dentro do JP. Refletindo a profissionalização do JP, os artigos que compõem o presente número foram inteiramente revisados na antiga gestão. Fazendo justiça à realidade, mantivemos o Conselho Editorial que efetivamente trabalhou para o presente número.

Para terminar, gostaria de compartilhar uma interessante carta que li recentemente na Scientific American
Brasil(8). No conto ("Sonho de mil gatos") do escritor $e$ roterista britânico Neil Gaiman, o mestre dos sonhos alerta que o sonho de um gato não representa nada, mas o sonho de mil gatos transforma-se em realidade. Gostaria de convidar todos os leitores a compartilhar desse sonho, que há muito se tornou realidade. Faço um convite, em especial aos autores que publicam sistematicamente em revistas internacionais, para que submetam um bom artigo original ao JP. Todos podem participar do JP, por exemplo, enviando um relato de caso clínico bem documentado que seja de interesse para toda a comunidade.

PROF. DR. GERALDO LORENZI FILHO

Editor do JP

\section{REFERÊNCIAS}

1. Queluz THAT. Admissão do Jornal de Pneumologia na SciELO Brasil: uma vitória com novos desafios. J Pneumol 2002;28:III.

2. Izique C. Produção crescente. Pesq FAPESP 2002;81:18-22.

3. Amin M, Mabe M. Impact factors: use and abuse. Elsevier Science [serial online], 2000 [cited 2000 october]. Available from: http://www. elsevier.com.

4. Vohora SB, Vohora D. Why are Indian journals' impact factors so low? Nature 2001;412:583.

5. Harnad S. The self-archiving initiative. Nature 2001;410:1024-5.

6. Curti M, Pistotti V, Gabutti G, Klersy C. Impact factor and electronic versions of biomedical scientific journals. Haematologica 2001;86:101520.

7. Alonso WJ, Fernandez-Juricic, E. Regional network raises profile of local journals. Nature 2002;415:471-2.

8. Grilo EWS. Sonho de mil gatos. Scientific American Brasil. 2002;6. 